\title{
HOW TO DEAL WITH CORPORATE SOCIAL RESPONSIBILITY IN FINANCIAL CRISIS
}

\author{
Ciprian-Dumitru Stoian ${ }^{1}$
}

\begin{abstract}
The aim of the paper is to examine the effects of periods of financial crisis on Corporate Social Responsibility (CSR) practices. This paper represents a theoretical research related to the latest developments in this field. We had documented our paper based on actual references on this matter. Firstly, in order to make correct assessments, this material seeks to examine the level of understanding in respect of two jointly concepts: CSR and financial crisis, as well as the resulted impact (on different stakeholders). We have also presented and commented on a new model that prescribes the reactions of CSR practices against the crisis and on different researches that have tried to quantify the link between the CSR and financial crisis. The result of our research granted us various opinions on attitude that companies should undertake in financial crisis: to cancel the CSR actions, to freeze the CSR actions or to be involved more in CSR actions. Based on our expertise, we assume and recommend that CSR efforts in financial crisis to be continued due to the fact that would mainly bring positive results for involved companies in mid and long-term basis.
\end{abstract}

Keywords: Corporate Social Responsibility, Financial crisis, Crisis Management

JEL Codes: $M 14$

\section{Introduction}

This paper mainly consists in a literature review on specific and actual theories by reviewing both events together: CSR and financial crisis. The purpose of the paper is to bring together actual developments in the research field of "CSR and financial crisis" and a model that makes a link between CSR and financial crisis. By having all these literature review, we can make assumptions, comments, set clear steps and conclude on further and thoughtful researches in this particular area.

Financial crisis and corporate social responsibility (CSR) are queries that have very much attracted in both academic and non-academic areas, as reflected through an increased number of recent studies developed on these topics. The main purpose of the paper is to identify companies' reactions reflected on CSR projects and, subsequently, directions of CSR strategies in the period of financial crisis.

It is important to mention that after the beginning of the financial crisis of 2008 , various companies have started to pursue cuts and savings strategies. Their objective was to minimize their expenses and to maintain their existence. (CSR) activities were also influenced by these strategies exercised by enterprises due to the crisis. As a result, CSR projects started to be diminished.

However, other companies considered their strategy in respect of not affecting CSR projects. Their wish was to establish and to develop business positions on the markets thorough the financial crisis and post-crisis. Such companies have been using CSR programmes as a marketing tool to mitigate also the potential lack of trust in their companies since the financial crisis, even though very difficult to recognize.

In order to have a concrete and actual model that intends to match together CSR and financial crisis, we have present, review and make specific comments about the model developed

\footnotetext{
${ }^{1}$ „Babeş-Bolyai” University of Cluj-Napoca, Romania, e-mail: ciprianst@yahoo.com
} 
by Yelkikalan and Kose (2012). This model intends to create the link between CSR and financial crisis, by assessing together two different concepts: the savings reactions of individuals and companies due to crisis and the strategies of businesses continuing and developing CSR even in times of crisis.

\section{Financial crisis and corporate social responsibility}

Financial crisis and CSR - these two concepts together are important to be assessed within the framework of nowadays economic downturn. Many ideas, different samples, various conferences, great studies and important economic experts have tried together to join specific expertise in order to find a credible answer in respect of how CSR actions were affected by financial crisis.

The financial crisis brought worldwide issues to companies, especially due to lack of liquidity. Therefore, CSR projects, as additional costs to business financially in the period of financial crisis, seemed to be deeply analyzed by the companies' representatives.

As a result, following the last years' economic worldwide situation, some of the specialists tried to identify a clear link between financial crisis and corporate social responsibility (CSR). In this respect, we have made introspection into specific literature, in order to review the opinions of various experts.

For example, Fernández and Souto (2009) investigate the results of the economic and financial crisis on CSR. They believe that both managers and stockholders are affected by the economic recession and it was difficult to identify a straight line in respect of the relationship between CSR and business economic performance. For many of the companies, CSR represent additional financial cost for the social initiatives. Moreover, by taking into account that a precise set of CSR framework is not to be known, seven issues were highlighted for CSR implementation in period of crisis: innovation, comfortable atmosphere, stakeholders' role, business strategy, market attitude, investor confidence and deep internal reflection. The problem of CSR implementation may be represented by the costs attached to this implementation.

Another specialist (Njoroge, 2009) examines the relation between current financial crisis and Kenyan multinational companies, as well as the effects of multinational companies in social projects and labor standards. The methodology of the research used consisted in a telephone interview survey and analysis of Covalence database. Njoroge's results were in the sense that economic downturn has no severe effect on labor standards while it has a negative effect on funding and implementing social projects.

Karaibrahimoglu (2010) observed CSR performance for 2007 (period before the financial crisis) and for 2008 (period of crisis especially in US markets). Methodology of the research consisted in a sample, based on Fortune 500 where 100 companies were randomly selected. The investigation of CSR performance was performed within content analysis of annual non-financial reports. Twenty nine indicators were investigated for estimating CSR performance and were classified into five stakeholders' areas for estimating CSR performance: employee, consumer, government, supplier and society. The presence of information for each of the indicators in CSR reports was scored with 1 and the absence of relative information with 0 . Results of the research show that companies decrease CSR projects because of a financial downturn. In order correctly position the decreases of CSR project, USA was in top comparing to other European and nonEuropean countries.

On the same side, Arevalo and Aravind (2010) investigate the impact of financial crisis to CSR by considering a part of the US companies (i.e. 271) that adopt the principles of United Nations Global Compact (UNGC). The results of the study were that in some cases CSR was considered as a starting point for improving business operation. Companies that integrate UNGC principles with lesser conformity were to be affected more by the financial downturn while companies that adopt a proactive policy concerning UNGC were affected less. Within the analysis 
tool of CEO statements, there were main six CSR priorities highlighted in time of crisis: building strong leadership teams, applying innovation to solve the most complex global problems, forming partnerships with NGOs, maintaining core commitment to global citizenship, engaging in global dialogue on human rights and joining global discussions on climate change.

We have also reviewed the study of Iyer (2012) about the firms that gain trust through CSR. He observed that banks and financial institutions in Asia were refining their CSR commitments. Since the banking crises and economic downturn in 2008, it is considered that financial institutions and banks have started to view CSR as a prerequisite for success in the long term. Many of financial institutions started to understand that CSR programmes are marketing tools to mitigate potential lack of trust in financial institutions in Asia since the financial crisis. This fact resides also from the reaction of the consumers in Asia that begin to show more interest in the companies that "do good".

All these studies cannot bring consensus on examining the effects of the crisis related to CSR. On one side, authors that studied this issue have determined that the financial problems brought by the crisis decreased the budget allocated to CSR activities and, as a result, had a negative effect on the CSR actions. On the other hand, there are opinions sustaining that being engaged in CSR activities is a good method for applying the opportunities brought by the crisis due to the positive effects of CSR activities and businesses and, subsequently, CSR may be seen as a part of the crisis environment.

We conclude that as a result of the review presented above, there are arguments to consider that companies engaged in CSR actions in financial crisis time would have to gain in a mid and long term basis. It is clear that there might be additional costs triggered at a current date, however by exploring a longer period of time a good financial result should be acquired. The CSR activities in financial crisis may also have an impact on consumers' reactions, as it is well known that clients (i.e. stakeholders of companies) are receptive when discussing about social actions.

\section{CSR and financial crisis: a win-win situation for companies and stakeholders}

In addition to our literature review, we present and comment on models and on other related studies that have tried to quantify the link between CSR and financial crisis.

Yelkikalan\&Kose (2012) have recently developed a model in which they tried to explain the effects of the crisis on CSR in different directions, by using Carroll's CSR pyramid. The main arguments of the model were that the reactions of CSR practices against the crisis change depending on the location of these practices in different dimensions of the CSR pyramid.

According to this model, there would be two major propositions that should be addressed:

- "Proposition 1: The Crisis poses a threat to the responsibility dimensions located at the base of the CSR pyramid" and

- "Proposition 2: The crisis poses an opportunity for the responsibility dimensions located at the top of the CSR pyramid."

In order to review the model, specific comments will be presented in accordance with each of the above propositions. 


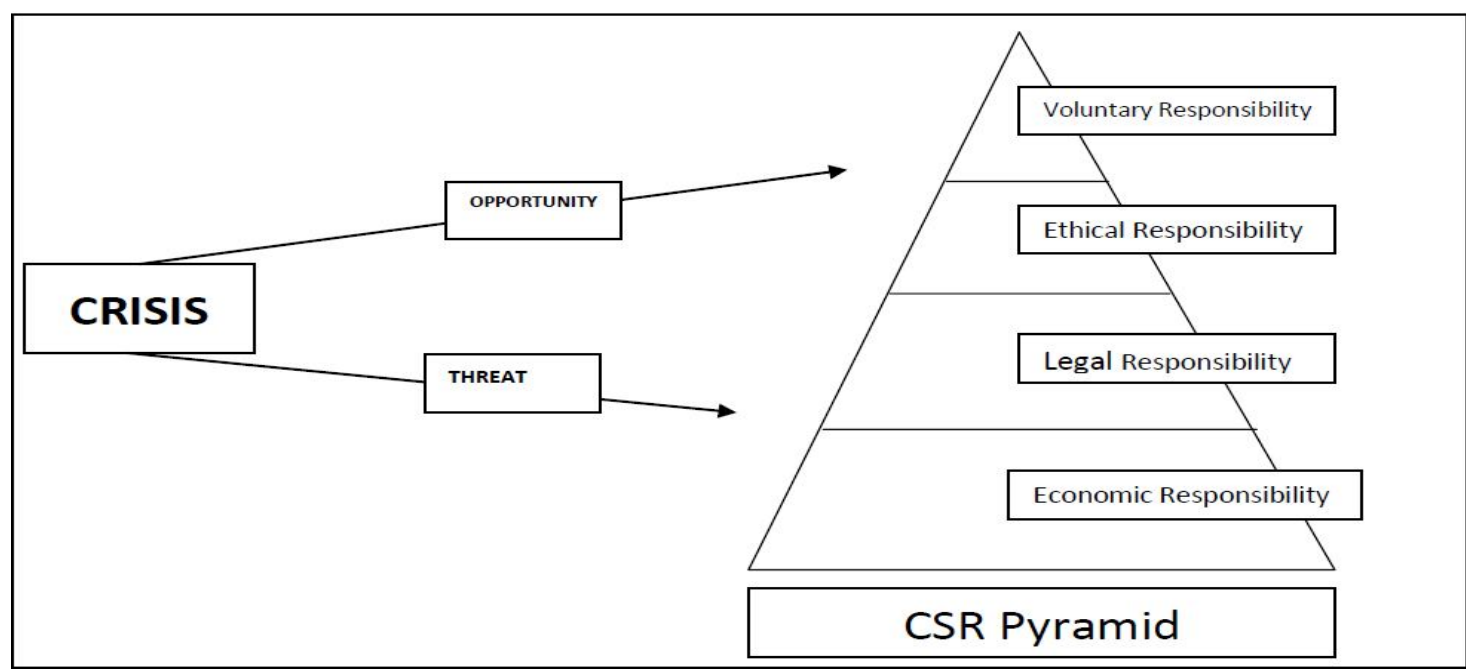

Figure no.1. - CSR affected by financial crisis

Source: (Yelkikalan, Kose, 2012)

The authors make a reference to A. H. Maslow human needs grouped in his "Hierarchy of Needs" theory (Maslow, 1943: 370-396). They make the assumptions that lower needs in case of individuals are also similar for companies. According to this, they consider that if economic crisis bring a threat in itself, then businesses would focus on managing actions for survival. The results of previous years' crisis were: uncertainty, financing difficulties, and decline in production levels and, of course, reducing staff. This first proposition tends to suggest that businesses made cuts to survive against the threats posed by the crisis, in order for companies to secure their first dimensions from Carroll CSR Pyramid. Moreover, it is believed that even the fact of keeping the business on-going could be seen as CSR for all the stakeholders. The size of the threat in relation with the crisis on the responsibility dimensions located at the bottom of the CSR pyramid is in parallel with the enterprise's rate of being affected by the crisis.

It is also believed that measures of the companies affected by the crisis were different from entity to entity, from sector to sector and, consequently, there would be differences in post-crisis CSR activities of the businesses in the sectors that have been the most affected by the crisis and the change for the businesses in sectors that have been less affected by the crisis.

Economic crisis after the 2008 financial crisis has also led to certain social problems. Social problems are referring to cut of jobs. In this context, companies (i.e. especially large companies) tended to freeze their number of employees and, why not, to hire more stuff. It is practically a different situation compared to proposition 1. In this case, businesses desire to make use of the opportunities in the crisis and, as a result, want to put CSR activities at the forefront in the crisis periods since it makes positive contributions to the society and the corporate reputation of the businesses. CSR may be positively affected by using the crisis opportunity by transforming the fundamental values of the business into an advantageous position.

The authors make a reference also to Iwacewicz-Orlowska and their opinion about positive correlation between CSR and long-term company performance. In times of crisis, CSR will both allow a better risk management and strengthen the sense of confidence in the companies that would be required for performing the activities to be needed in the course of the crisis (IwacewiczOrlowska, 2010). Due to reasons as such, especially large-scale and / or global businesses have chosen to maintain their effective and active CSR practices they have been continuing for many years in the crisis period as well. It is also reflected the companies' scale importance in front of the financial crisis. It is well known that huge MNCs are to be easily put in situation to fire personnel comparing to lower companies, which are interested to maintain and to conserve good relationship 
with their employees. Proposition 2 of the model is also sustained by a study carried out by Giannarakis and Theotokas in 2011. The Greek authors have used Global Report Initiatives (GRI) in order to assess the impact of financial crisis on the performance of CSR. They conducted a study on 112 large companies for the period covering 2007-2010. According to this study, CSR performance increased in 2007 and 2008. The reason for this increase was suggested to be the businesses' aims for maintaining their brand value and previous gained assets.

Other argument used by Yelkikalan and Kose in order to sustain the use of opportunity during the crisis in respect of CSR actions is related to an increased number of organizations engaged in CSR ratings in recent years and the importance of these ratings.

Moreover, another study resulted in positive and significant correlation between different variables, which did not change in the pre-crisis and post-crisis periods (Selvi, Wagner and Turel, 2010: 285). The study analysed above is relevant on both sides. Practically, even if negative and positive effects on CSR actions are presented, definitely the overall result may be seen as a fair attitude of companies faced with financial crisis. Many may argue that cost savings strategies were a method of CSR for companies, in order to avoid the disaster: bankruptcy. Others may argue that taking in front the crisis opportunity by developing CSR actions may result in good financial outcomes and a quick exit from financial crisis. There might be also specialists to consider the viceversa of the situations and, why not, a mixed situation.

In all potential cases, Yelkikalan and Kose were cautioned and correct to present Carroll's CSR pyramid (derived from Maslow pyramid of needs) - related to the opportunities and threats of financial crisis, in respect of influences regarding CSR actions. The result of the study is that either strategy adopted by a company during the financial crisis in respect of CSR policy may be covered and explained by this model and may trigger advantages and disadvantages for companies involved.

We also think that it would be indicated that business responsible persons to perceive the crisis as a threat to economic activities and take precautions on costs and, subsequently, on CSR programmes. At the same time, the business responsible persons should continue to act responsible (i.e. through CSR activities) at least at a lower level (e.g. philanthropy) without interruption in times of crisis. The strategy of perceiving the crisis both as opportunity and threat (i.e. related also to CSR activities) would help companies to continue their business in financial crisis and would assure their long-term profitability of the business.

\section{Conclusions}

During the last decades, CSR project increased, mostly in developed economies. This paper's objective was to examine the effects of periods of crisis on CSR practices. Initially, introspection through literature was pursued, in order to assess a potential link between financial crisis and its effects on CSR. The results of the literature review were controversial, as the experts concluded differently: some of them considered that no precise link can be defined as financial crisis and CSR are two different concepts, while others considered both positive and negative reactions of financial crisis to CSR. Our conclusion is that in any circumstances, a correct approach when dealing with CSR practices in financial crisis would be on selecting the "green" colour in respect of continuing CSR projects.

Furthermore, the results of assessing a recent study carried out by Yelkikalan and Kose, from Canakkale Onsekiz Mart University from Turkey provided us with the parallelism between Carroll's CSR pyramid and Maslow's pyramid of hierarchy of needs and reflected the necessity to consider primarily the needs/activities that are located at the bottom of the pyramid in times of crisis (threat component of the model). Moreover, CSR activities represent a great tool for making use of the opportunities in the environment generated due to the crisis and indicated good results for "businesses adopting CSR concept and executing it at the level of philanthropy with a sense of continuity carried on their CSR activities without interruption in times of crisis" (opportunity component of the model). We may also conclude that by taking into consideration this model as 
well as other theories that have tried to quantify CSR and financial crisis (presented in the paper), different answers can be given to the "what is the direction of the impact of crisis on CSR activities?" question. Some of the answers direct us to the level of closing down all CSR activities in financial crisis due to the fact that it generates additional costs for involved companies. Other answers are perceiving that a good reactions of companies would be to freeze their CSR actions in those periods of financial crisis, while a third opinion states that companies should be positively influenced in their CSR actions because financial crisis should be seen as an opportunity of rethinking and growing.

As already presented, financial crisis encounters various effects on different levels of CSR and presents different perspectives. Our conclusion is that business equilibrium must be applied in order to correctly develop CSR strategies during the financial crisis. We consider that companies should be encouraged and incentivized (e.g. reduce tax burden, fiscal measures) to continue their development and correct engagement in CSR actions. On a mid and long-term run, we consider that the advantage would be on the companies' side.

\section{References}

1. Arevalo J.A., Aravind D., 2010. The impact of the crisis on corporate responsibility: the case of UN global compact participants in the USA. Corporate Governance, 10(4), pp. 406420.

2. Carroll A.B., 1991. The Pyramid of Corporate Social Responsibility: Toward the Moral Management of Organizational Stakeholders. Business Horizons, July - August, 39-48.

3. Fernández B., Souto F., 2009. Crisis and Corporate Social Responsibility: Threat or Opportunity?, International Journal of Economic Sciences and Applied Research, 2 (1), pp. 36-50

4. Giannarakis G., Theotokas I., 2011. The Effect of Financial Crisis in Corporate Social Responsibility Performance, International Journal of Marketing Studies, Vol. 3, No. 1, pp. $2-10$

5. Iyer B., 2012. Firms gain trust through CSR. Campaign Asia - Pacific. Retrieved from http://search.proquest.com/docview/1221276945?accountid=15533 Accessed: April 2013

6. Iwacewicz-Orlowska M.A.A., 2010. Corporate Social Responsibility and Global Crisis, "About the global crisis" conference, Turkey.

7. Karaibrahimoglu Y.Z., 2010. Corporate social responsibility in times of financial Crisis, African Journal of Business Management, 4(4), 382-389, pp. 382-389

8. Maslow A. H., 1943. A theory of human motivation, Psychological Review, Vol 50(4), Jul 1943, pp. 370-396.

9. Njoroge J., 2009. Effects of the global financial crisis on corporate social responsibility in multinational companies in Kenya, Covalence Intern Analyst Papers, available at: www.covalence.ch/docs/Kenya-Crisis.pdf. Accessed: April 2013

10. Schiopoiu Burlea A., Radu C., Craciun L., Ionascu C., Mitrache M., Lolescu R., 2010. The Relationship between Financial Crisis, Corruption, and Corporate Social Responsibility in Romania. Management and Marketing Journal, University of Craiova, Faculty of Economics and Business Administration, vol. 0(1), pp. 65-72.

11. Selvi Y., Wagner E., Türel A., 2010. Corporate Social Responsibility in the time Of Financial Crisis: Evidence from Turkey, Annales Universitatis Apulensis. Series Oeconomica, Number 12, Issue 1, pp. 281-290

12. Yelkikalan N., Kose C, 2012. The effects of the financial crisis on corporate social responsibility, International Journal of Business and Social Science, Vol. 3, No. 3, pp. 292300 